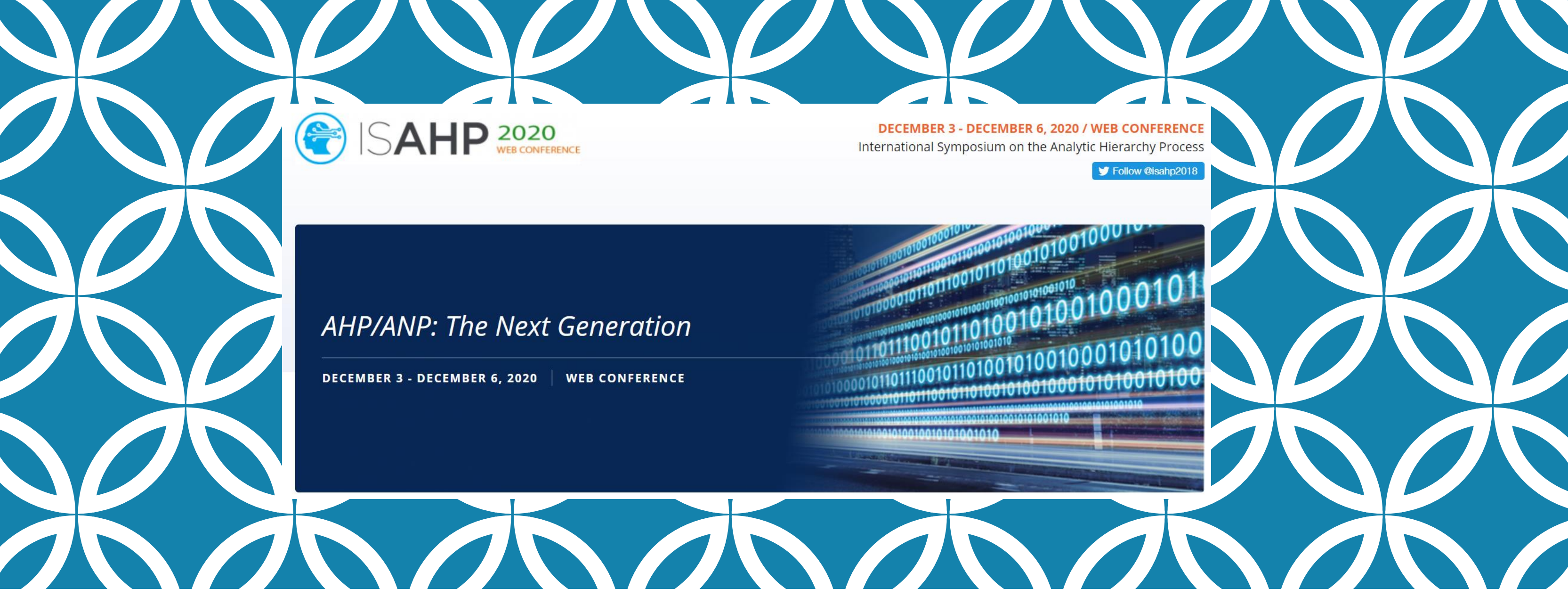

\title{
A DECISION SUPPORT TOOL FOR HOSPITAL PROJECT SUSTAINABILITY EVALUATION
}

Carlotta Patrone Eng, Phd Antonio Latora, Eng Roberto Revetria, Prof 


\section{AIM OF THE STUDY}

- This study aims to develop a Decision Support Tool (DST) able to evaluate the sustainability of strategic projects which could be implemented in a hospital context.

- Strategies are usually declined into different projects but carrying out several simultaneous plans is not always sustainable.

- To the best of our knowledge, there are no consolidated methodologies allowing the objective quantification of the healthcare's project sustainability.

- The present research was born from the need to translate the sustainability of all strategic projects to the hospital's board of directors composed by people with different professional extractions.

- For this reason, the authors have tried to answer the question of translating the sustainability of a strategic health project into a single indicator. 


\section{HYPOTHESES/OBJECTIVE}

-A double Multi-Criteria Decision Analysis was realized by the traditional Analytic Hierarchy Process and the more recent Value-Analytic Hierarchy Process, in order to implement a sustainability index named Sustainability Group Global Rating. 


\section{RESEARCH DESIGN/METHODOLOGY}

This study was based on a double MCDA realized by the traditional AHP and t e recent Value-Analytic Hierarchy Process (V-AHP). Both methods are able to realize a quick and easy multi-criteria decision process. The AHP was developed in late Seventies allowing a pairwise comparisons of criteria and/or items. It realizes an overall ranking of the items leading towards a "rational decision". Compagno et al. simplifies the traditional AHP methodology introducing the Value-Analytic Hierarchy Process (V-AHP) formulated combining the traditional AHP rating on qualitative criteria with the "lean" rating on quantitative criteria, this latter where the "lean" rating is obtained by the ratio between the

value of performance related to the $i$-th item and the sum of performance values related to all the items under investigation. The hierarchy for this investigation, depicted in Figure 1, was developed according to the holistic vision of the sustainable healthcare system defined by Fineberg. 


\section{RESEARCH DESIGN/METHODOLOGY}

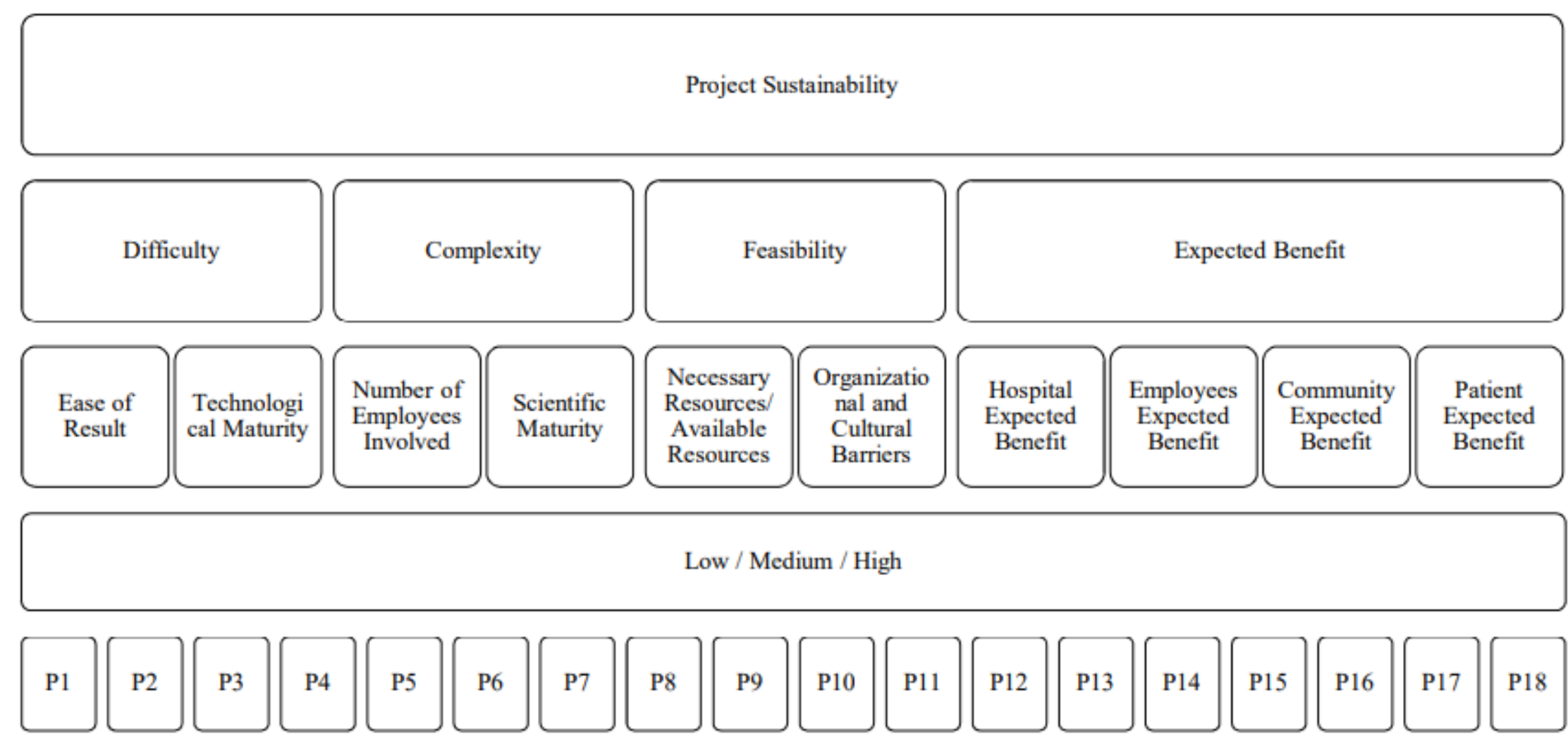




\section{RESEARCH DESIGN/METHODOLOGY}

\begin{tabular}{ll}
\hline PROJECT ID & PROJECT DESCRIPTION \\
\hline P 1 & Process engineering and computerization \\
P 2 & Master plan for the new hospital: technical activities, lows and paths \\
P 3 & Open hospital \\
P 4 & The new professions: the pharmacologist, clinical interpreter \\
P 5 & Intensity of care and tutoring \\
P 6 & Business: the standardization of best practices lean \\
P 7 & DMT development \\
P 8 & Individual performance evaluation \\
P 9 & Adherence to ethical values: the ethical charter \\
P 10 & Training \\
P 11 & Appropriateness and efficiency \\
P 12 & Morphic imaging - functional \\
P 13 & Mini-invasiveness \\
P 14 & Robotic technologies \\
P 15 & Genomics \\
P 16 & Technologies for the elderly \\
P 17 & Research \\
P 18 & IRCCS “aging" and research activities \\
\hline
\end{tabular}




\section{RESEARCH DESIGN/METHODOLOGY}

\begin{tabular}{ccccc}
\hline PROJECT ID & NSGGR & RANKING NSGGR & 2017 NAIR & 2018 NAIR \\
\hline P8 & 1 & 1 & 0,5 & Not available \\
P2 & 0,9638 & 2 & 1 & 0,75 \\
P11 & 0,9448 & 3 & 0,8276 & Not available \\
P1 & 0,8931 & 4 & 1 & 1 \\
P7 & 0,8773 & 5 & 0,95 & 0,99 \\
P5 & 0,8716 & 6 & 0,75 & 1 \\
P10 & 0,845 & 7 & 1 & 1 \\
P9 & 0,8319 & 8 & 1 & 0,5 \\
P17 & 0,8284 & 9 & 1 & 1 \\
P16 & 0,8282 & 10 & 0,75 & 1 \\
P3 & 0,8035 & 11 & 1 & 1 \\
P6 & 0,7874 & 12 & 0,645 & 0,875 \\
P18 & 0,7225 & 13 & 1 & 1 \\
P13 & 0,7139 & 14 & 0,75 & 0,75 \\
P12 & 0,7129 & 15 & 1 & 1 \\
P4 & 0,7045 & 16 & 1 & 1 \\
P15 & 0,6787 & 17 & 1 & 0,566 \\
P14 & 0,6368 & 18 & 0,75 & 0,75 \\
\hline
\end{tabular}




\section{LIMITATIONS}

This research has several limitations: the normalized Sustainability Group Global Rating (NSGGR) was carried out by interviews realized in 2016 on a set of 18 three-year projects starting from 2017. It should be appropriate, as shown by the heterogeneity of the results over the years, an annual refresh of the Decision-Making process in order to have an updated index including new information and level of knowledge available. Secondly, NAIR should be refined. In fact, it has been demonstrated that management has often given projects time schedule depending on no-controllable external factors. However, this last criticality does not depend so much on the method as on the performance cycle implemented. 


\section{CONCLUSIONS}

The normalized Sustainability Group Global Rating (NSGGR) depicted in this study is a qualiquantitative index useful to Decision-Makers in order to realize forecast on the sustainability evaluation of strategic projects implementable in the hospital context. On the contrary, the Normalized Annual Implementation Rating (NAIR) represents a progress index of implemented projects. The gap between NAIR and NSGGR, here defined Annual Sustainability Critical Project (SCP), measures the distance between the strategic plan of the Board of Directors and the operations realized by the Line Directions. Ideally these values should be zero but it never happens. A positive value means that the result achieved is higher than the sustainability index and therefore less ambitious targets have been given.

On the contrary, if it is a negative value, the project has been underestimated or too ambitious targets have been given. This Decision Support Tool, developed for the hospital context, can be applied to any organization with easy customization, even if further researches are necessary to narrow listed limitations. 
THANKS FOR YOUR ATTENTION 